\title{
Glomerular Basement Membrane
}

\author{
BIOSYNTHESIS AND CHEMICAL COMPOSITION IN \\ THE STREPTOZOTOCIN DIABETIC RAT
}

\author{
Paul J. Beisswenger \\ From the George S. Cox Medical Research Institute, Department of Medicine, \\ University of Pennsylvania, and the Veterans Administration Hospital, \\ Philadelphia, Pennsylvania 19104
}

A в S T R A C T To study the effect of streptozotocin induced diabetes on glomerular basement membrane (GBM) synthesis, an isolated rat glomerular preparation has been developed, and its metabolic properties have been defined. The chemical composition of normal rat $\mathrm{GBM}$ isolated from this preparation closely resembles human GBM. Incubation with $\left[\mathrm{U}_{-}{ }^{14} \mathrm{C}\right]$ lysine leads to prompt incorporation of label into GBM and the subsequent appearance of labeled hydroxylysine. A 1-h lag before detection of labeled hydroxylysine in GBM suggests a delay in the release of GBM precursors. Significantly lower counts appeared in the nondialyzable fraction of the medium than in insoluble GBM during pulse-chase experiments, and labeled hydroxylysine accounted for a lower portion of the total counts in the medium $(0.85 \%)$ than in the GBM $(1.98 \%)$.

Isolated glomeruli were prepared from streptozotocin diabetic rats of 4-6 wks duration. After incubation with $\left[\mathrm{U}-{ }^{14} \mathrm{C}\right.$ ] lysine recovery of label in diabetic GBM (88.98 $\pm 8.26 \mathrm{nmol} / \mathrm{g}$ GBM) did not differ from age matched controls $(82.52 \pm 8.26 \mathrm{nmol} / \mathrm{g}$ GBM $)$. In pulsechase experiments recovery of label in hydroxylysine of diabetic GBM $(0.473 \pm 0.082 \mathrm{nmol} / \mathrm{g}$ GBM $)$ did not differ from age matched controls $(0.567 \pm 0.065 \mathrm{nmol} / \mathrm{g}$ GBM). These findings indicate normal rates of GBM synthesis and hydroxylation of lysine residues in animals with streptozotocin diabetes.

This work was presented in part at the National Meeting of the American Federation for Clinical Research, Atlantic City, N. J., May 1974, and published in abstract form in Clin. Res. 1974. $22: 460 \mathrm{~A}$.

Dr. Beisswenger was a Research and Education Associate, Philadelphia Veterans Administration Hospital. His current address is The Dartmouth-Hitchcock Medical Center, Hanover, N. H. 03755.

Received for publication 14 February 1975 and in revised form 1 June 1976.
The chemical composition and morphology of the GBM was then studied in rats with long term streptozotocin diabetes (14 mo) to determine if the increase in hydroxylysine and glucosyl galactose and the decrease in lysine previously noted in the GBM in long-term human diabetes occurs in the rat. Except for minor changes in proline and arginine content, the chemical composition of diabetic rat GBM did not differ from age matched controls. while light microscopic studies of diabetic and control kidneys revealed equal degrees of mesangial and peripheral GBM changes.

\section{INTRODUCTION}

Pathologic changes in the capillary wall characterized by thickening of the basement membrane have been recognized in multiple vascular beds of long-term diabetics $(1,2)$. Diabetic intercapillary glomerulosclerosis and resultant renal failure, however, continue to be the greatest single cause of mortality and morbidity in patients with the juvenile onset type of diabetes $(3,4)$. This lesion, first described by Kimmelstiel and Wilson (5). represents the most specific diabetic microvascular lesion, although diffuse thickening of the glomerular basement membrane $(\mathrm{GBM})^{\mathbf{1}}$ occurs with equal or greater frequency $(6,7)$. Glomerular lesions resembling those seen in human diabetes have also been described in experimental animals with both genetic $(8,9)$ and experimental diabetes (10-13) suggesting that environmental factors may play a role in their pathogenesis. For example, recent electron microscopic studies have demonstrated that modest basement membrane thickening occurs in the GBM of rats with long-term streptozotocin induced diabetes (13). This and other studies

\footnotetext{
${ }^{1}$ Abbreciation used in this paper: GBM, glomerular basement membrane.
} 
imply that rats with experimental diabetes may serve as a useful model for the study of human diabetic microangiopathy.

In addition to the basement membrane thickening observed in patients with diabetes mellitus, a distinct chemical change has been described in the GBM of some patients with diabetes of long duration $(14,15)$. The diabetic GBM shows an increase in hydroxylysine with a concomitant decrease in lysine residues as well as an increase in the disaccharide glucosyl-galactose covalently bound to hydroxylysine. In addition, significant increases in GBM hydroxyproline and glycine content and decreases in valine and tyrosine are also observed in diabetic GBM. Since a subunit rich in glucosyl-galactose, hydroxylysine, glycine, and hydroxyproline and poor in lysine, valine, and tyrosine has been described in bovine GBM (16), it is possible that the change in diabetic GBM could represent accumulation of a similar carbohydrate rich subunit. No information on the chemical composition of GBM in experimental animals with longterm diabetes is currently available.

Our current information regarding the control of GBM biosynthesis is inadequate. Several studies which utilized experimental animals have suggested that the thickening of basement membrane in diabetes is due to accelerated synthesis. By utilizing alloxan diabetic rats, Spiro and Spiro (17) have demonstrated increased activity of renal glucosyl transferase, the enzyme that adds the terminal glucose residue to the glucosyl-galactose disaccharide in GBM. In another study Cohen and Vogt (18) have suggested that glomeruli isolated from pancreatectomized rats incorporate increased amounts of labeled lysine into a subcellular fraction, and more recently Khalifa and Cohen (19) have demonstrated increased glomerular lysyl hydroxylase activity in streptozotocin diabetic rats. Wahl and his colleagues, on the other hand, could not demonstrate increased incorporation of labeled glucose into GBM when glomeruli from alloxan diabetic animals were compared with nondiabetics (20).

To study GBM biosynthesis an isolated rat glomerular preparation has been developed. and its metabolic parameters have been defined. The viability and metabolic properties of isolated glomeruli have previously been documented by several other investigators (20-24). The incorporation of $\left[\mathrm{U}_{-}{ }^{14} \mathrm{C}\right]$ lysine into $\mathrm{GBM}$ by this preparation provides information on the rates of GBM biosynthesis. The subsequent incorporation of labeled hydroxylysine residues into GBM indicates that in addition to providing information on GBM synthesis this preparation may furnish useful data on lysyl hydroxylase activity. This enzyme is of special interest since hydroxylation of lysine residues presumably precedes the addition of galactose and glucose residues to GBM
(25). By utilizing this preparation, glomeruli which have been isolated from normal and streptozotocin diabetic animals, have been studied to determine their rates of incorporation of labeled lysine and hydroxylysine into GBM.

To determine the effect of long-term experimental diabetes on the chemical composition of the GBM, streptozotocin diabetic rats and age matched controls have been maintained for 14 mo before isolation and chemical analysis of their GBM. Information obtained from these experiments is necessary to evaluate the results of the GBM biosynthetic studies and provides useful information on the relative role played by genetic and environmental factors in the pathogenesis of diabetic microangiopathy.

\section{METHODS}

General. Streptozotocin was obtained from Dr. William Dulin (Upjohn Corp., Kalamazoo, Mich.) and Dr. Howard Katzen (Merck, Sharp and Dohme, Rahway, N. J.) and administered i.v. in $0.01 \mathrm{M}$ citrate buffer, $\mathrm{pH}=4.5$, at a dose of $70-90 \mathrm{mg} / \mathrm{kg}$; $90-100 \mathrm{~g}$ male Wistar rats were used, and controls were injected with buffer alone. Lactate test kits were obtained from C. F. Boehringer and Sons, Mannheim, Germany. [ $\mathrm{C}-^{14} \mathrm{C}$ ] glucose $(5 \mu \mathrm{Ci} / \mu \mathrm{mol})$ and $\left[\mathrm{U}-{ }^{14} \mathrm{C}\right]-$ lysine $(265-312 \mu \mathrm{Ci} / \mu \mathrm{mol})$ were obtained from New England Nuclear Corp., Boston, Mass.; $\alpha, \alpha^{\prime}$-dipyridyl and cyclohexamide (Sigma Chemical Co., St. Louis, Mo.), Llactic acid sodium (Schwarz/Mann Div., Orangeburg, N. Y.), ascorbic acid (Nutritional Biochemicals Corp., Cleveland, Ohio), and $\alpha$-ketoglutarate (Matheson Gas Products, East Rutherford, N. J.) were used as indicated.

Preparation of glomeruli for incubation. The animals were sacrificed by decapitation, and their kidneys were immediately perfused with cold $0.9 \% \mathrm{NaCl} \quad(\mathrm{pH}=7.40)$ containing 5 or $30 \mathrm{mM}$ glucose until blanching occurred. The kidneys were removed, bisected, and placed in cold Krebs-Ringers bicarbonate buffer $(\mathrm{pH}=7.4)$ containing 5 or $30 \mathrm{mM}$ glucose and constantly bubbled with $95 \% \mathrm{O}_{2}$ $5 \% \mathrm{CO}_{2}$. The renal cortex was removed in thin slices with a Stadie-Riggs tissue slicer and placed in a similar buffer. Glomeruli were prepared from the cortical slices on stainless steel sieves by a modification of a technique previously used for bovine and human glomeruli $(15,26)$. Because of the smaller size of rat glomeruli, the cortical tissue was disrupted in 5-g portions with the bottom of a $150-\mathrm{ml}$ beaker on 3-inch 150-mesh sieves. The suspension of material passing through this sieve was in turn passed through a 150 mesh sieve in series with a 200-mesh sieve, and the glomeruli on the 200 -mesh sieve were washed two times with $75 \mathrm{ml}$ of $0.9 \%$ sodium chloride $(\mathrm{pH}=7.40)$ and transferred for centrifugation at $12,000 \mathrm{~g}$ at $4^{\circ} \mathrm{C}$. The pellet was suspended in Krebs-Ringers bicarbonate buffer, and samples were taken for incubation and nitrogen determination. The preparations consistently contained greater than 95\% glomeruli when differential counts were performed by phase microscopy.

Metabolic characteristics of glomeruli. All incubations were carried out in Krebs-Ringers bicarbonate buffer $(\mathrm{pH}$ $=7.40$ ) in a total volume of $1.0 \mathrm{ml}$ with constant shaking, at $37^{\circ} \mathrm{C}$. The preparations were intermittently gassed with either $95 \% \mathrm{O}_{2}$ or $95 \%$ air containing $5 \% \mathrm{CO}_{2}$.

Lactate was determined by lactic dehydrogenase (27) on 
perchloric acid filtrates of medium from incubations performed with or without $5 \mathrm{mM}$ glucose. ${ }^{14} \mathrm{CO}$. production at 2,4 , and $6 \mathrm{~h}$ was determined by incubating glomeruli isolated from three kidneys in flasks containing $2 \mathrm{ml}$ of Krebs' Ringers bicarbonate buffer and $\left[\mathrm{U}^{14} \mathrm{C}\right]$ glucose $(0.1$ $\mu \mathrm{Ci} / \mu \mathrm{mol}) .{ }^{14} \mathrm{CO}_{2}$ was collected on Hyamine saturated filter paper after acidification of the medium with $0.5 \mathrm{ml} 1.0 \mathrm{~N}$ $\mathrm{H}_{2} \mathrm{SO}_{4}$ and shaking at $37^{\circ} \mathrm{C}$ for an additional hour (28). Total counts were determined on these samples and on appropriate reagent blanks in Bray's solution utilizing a liquid scintillation spectrometer (model ABAC SL 40, Intertechnique Instruments, Inc., Dover, N. J.).

$\left[U_{-}{ }^{14} C\right]$ lysine incorporation into $G B M$. In these studies glomeruli from 20-30 kidneys were incubated in KrebsRingers bicarbonate buffer containing $20 \mu \mathrm{M}\left[\mathrm{U}-{ }^{14} \mathrm{C}\right]$ lysine $(312 \mathrm{mCi} / \mathrm{mmol})$. Glomeruli from normal animals were incubated in buffer containing $5 \mathrm{mM}$ glucose while diabetic tissues were incubated in medium containing $30 \mathrm{mM}$ glucose. Incubations were carried out for periods of time ranging from $20 \mathrm{~min}$ to $4 \mathrm{~h}$, or the tissue was exposed to a [U${ }^{14} \mathrm{C}$ ]lysine pulse of $1 \mathrm{~h}$ followed by a chase with buffer containing $0.25 \mathrm{mM} \mathrm{L}$-lysine for $1-3 \mathrm{~h}$.

To terminate the incubation, an aliquot of stock solution containing $\alpha, \alpha^{\prime}$-dipyridyl and cyclohexamide was added to achieve a concentration of $1.0 \mathrm{mM}$ and $100 \mu \mathrm{g} / \mathrm{ml}$, respectively. The glomerular pellet was washed twice with cold $0.15 \mathrm{M} \mathrm{NaCl}$ containing similar concentrations of $\alpha, \alpha^{\prime}-$ dipyridyl and cyclohexamide and immediately frozen in dry ice and alcohol.

To prepare GBM the glomerular pellet was suspended in cold $1.0 \mathrm{M} \mathrm{NaCl}$, sonicated with a $3-\mathrm{mm}$ diameter probe of a Sonifier cell disruptor (Ultrasonics Systems, Inc., Farmingdale, L. I., N. Y.) at $60 \mathrm{~W}$ for $45 \mathrm{~s}$ on ice, and washed with cold $1.0 \mathrm{~N} \mathrm{NaCl}$ and distilled water as previously described (15). Hydrolysis was performed in $6.0 \mathrm{~N}$ constant boiling $\mathrm{HCl}$ under nitrogen at $105^{\circ} \mathrm{C}$ for $24 \mathrm{~h}$, and the acid was removed under vacuum at $50^{\circ} \mathrm{C}$.

The component amino acids were separated by ion exchange chromatography using the short column of the Beckman model 120C Amino Acid Analyzer (Beckman Instruments, Inc., Fullerton, Calif.). Two-thirds of the effluent was diverted by a stream splitter to a fraction collector for scintillation counting, while amino acid composition was determined with the remaining one-third. $1-\mathrm{ml}$ samples of the effluent were counted in Aquasol (New England Nuclear, Boston, Mass.) by utilizing the liquid scintillation spectrometer. Counts were considered significant if they fell outside the $99 \%$ confidence limits calculated for background by a method described by Steinberg and Udenfriend (29).

The nitrogen content of the basement membrane was determined after solubilization of a sample of GBM in $0.1 \mathrm{~N} \mathrm{NaOH}$ at $37^{\circ} \mathrm{C}$ and digestion with $50 \% \mathrm{H}_{2} \mathrm{SO}_{4}(26)$. The amount of dry GBM was determined for each preparation by using a nitrogen content of $9.65 \%$ as determined by digestion of GBM of known composition. The lysine and hydroxylysine content of each sample, calculated from the amino acid analyzer, was also used to determine the specific activity of $\left[\mathrm{U}-{ }^{14} \mathrm{C}\right]$ lysine and $\left[\mathrm{U}-{ }^{14} \mathrm{C}\right]$ hydroxylysine in the GBM.

Labeled lysinc and hydroxylysine in nondialy able fraction of medium. Preliminary studies were carried out to quantify the appearance of $\left[{ }^{14} \mathrm{C}\right]$ lysine and $\left[{ }^{14} \mathrm{C}\right]$ hydroxylysine in the medium during pulse-chase experiments. In two separate experiments, each utilizing glomeruli isolated from 10 normal rats, a 1 -h pulse with $\left[{ }^{14} \mathrm{C}\right]$ lysine $(312 \mathrm{mCi} / \mathrm{nmol})$ was followed by a 3-h chase period in Krebs-Ringers bicarbonate containing $5 \mathrm{mM}$ glucose and $0.25 \mathrm{mM}$ lysine. Incubations were performed at $37^{\circ} \mathrm{C}$ as previously described. After terminating the incubation by addition of $\alpha, \alpha^{\prime}$-dipyridyl and cyclohexamide to achieve concentrations of $1.0 \mathrm{mM}$ and $100 \mu \mathrm{g} / \mathrm{ml}$, respectively, the samples were spun at 15,000 $g$ at $4^{\circ} \mathrm{C}$ and the media from the two incubations were pooled. The medium was extensively dialyzed against 2.5 $\mathrm{m} \mathrm{M}$ L-lysine in distilled water at $4^{\circ} \mathrm{C}$ until constant specific activity was achieved. The dialysate was then taken to dryness in an Evap-o-Mix (Rotary Evapo-Mix, Buchler Instruments, Div. Searle Analytic, Inc., Fort Lee, N. J.) at $30^{\circ} \mathrm{C}$ and hydrolyzed under nitrogen in constant boiling $6.0 \mathrm{~N} \mathrm{HCl}$ at $105^{\circ} \mathrm{C}$ for $24 \mathrm{~h}$. Counts were determined on fractions corresponding to lysine and hydroxylsine as previously described.

GBM composition in long-term diabetic animals. Streptozotocin was administered $(50 \mathrm{mg} / \mathrm{kg}$ ) to male, caesarian delivered Fisher rats (Charles River Breeding Laboratory, Wilmington, Mass.) weighing $150-225 \mathrm{~g}$, and blood glucose was measured within $48 \mathrm{~h}$ and then bi-monthly for $14 \mathrm{mo}$. (Diabetic and control rats were provided and maintained by Dr. Monroe Glitzer and Dr. Howard Katzen, Merck Institute for Therapeutic Research, Rahway, N. J.) Animals were considered diabetic if their blood glucose values consistently exceeded $300 \mathrm{mg} / 100 \mathrm{ml}$. Age and sex matched controls were maintained under identical conditions. At the end of the study period the animals were sacrificed by decapitation, and their kidneys were removed and frozen after obtaining a piece of tissue for fixation in buffered formalin $(\mathrm{pH}=7.0)$ for light microscopic studies. 85 diabetic animals were considered suitable for study and were compared with 142 controls. Glomeruli were prepared by the use of stainless steel sieves by a method similar to that described for in vitro studies. For the preparation of basement membrane, five equal portions of glomeruli from both diabetic and control animals were disrupted by sonication as previously described. During sonication the degree of glomerular disruption was evaluated by periodic examination of each sample by phase microscopy. In several control and diabetic samples an additional 15 to $30 \mathrm{~s}$ of sonication were required to achieve optimal tissue disruption. After washing the GBM with cold $1.0 \mathrm{M} \mathrm{NaCl}$ and cold distilled water as previously described (15) a portion of each GBM sample was hydrolyzed in constant boiling $\mathrm{HCl}$ under nitrogen at $105^{\circ} \mathrm{C}$ for $24 \mathrm{~h}$. After removal of the acid under vacuum at $50^{\circ} \mathrm{C}$ amino acid and glucosamine analysis were performed on a Beckman model 120C Amino Acid Analyzer. Correction factors for the loss of serine and threonine were determined by timed hydrolysis of GBM and extrapolation of the values to zero time by the method of least squares (26). One-half cystine and glucosamine were corrected by using the yields of $85 \%$ and $69 \%$, respectively. The loss of one-half cystine was determined as previously described (15), while that of glucosamine was determined by the hydrolysis of standards under conditions similar to those used for cleavage of GBM peptide bonds. Although significant destruction of glucosamine occurs under these conditions and the destruction of free glucosamine might differ somewhat from that in glycosidic linkage, the small amount of rat GBM available for analysis dictated the use of the same sample for amino acid and glucosamine determination. The values obtained after correction were considered useful for comparative purposes. Analyses of glucose, galactose, mannose, and fucose were performed as previously described by gas-liquid chromatography utilizing a 12 -foot $15 \%$ EGS column on a Packard 
Gas Chromatograph, Packard Instrument Co., Downers Grove, Ill. (30). Since the yields of galactose standards were $88 \%$, galactose values determined on GBM were subsequently corrected. Statistical analysis of data from glomerular incubations and GBM compositional studies were performed by the $t$ test. Histologic studies of diabetic and control tissues were performed by Dr. Joseph Williamson of the Department of Pathology, Washington University, St. Louis, Mo.

\section{RESULTS}

The amino acid composition of GBM isolated from control rats closely resembles that of normal human $(14$, 31,32 ) and bovine (33) GBM (Table I) and is similar to that found in prior studies of rat $\operatorname{GBM}(34,35)$. Analysis of the carbohydrate content of rat GBM revealed the presence of glucose, galactose, mannose, fucose, and glucosamine (Table II), all of which have previously been found in human and bovine GBM.

Incubations of glomeruli with [U- $\left.{ }^{14} \mathrm{C}\right]$ glucose for $6 \mathrm{~h}$ led to the linear production of ${ }^{14} \mathrm{CO}_{2}$ indicating viability for this period of time. In two experiments the glomeruli produced 3.12 and $4.26 \mu$ moles of lactate $/ 100 \mathrm{mg}$

\section{TABLE I}

A mino Acid Composition of GBM* from Long-Term Diabetic Rats and Controls $\ddagger$

\begin{tabular}{lrrr}
\hline \multicolumn{1}{c}{ Component } & \multicolumn{1}{c}{ Controls } & \multicolumn{1}{c}{ Diabetics 8} & \\
\hline & residue/1.000 amino acid residues & $P$ \\
3-Hydroxyproline & $10.28 \pm 0.28$ & $9.42 \pm 0.51$ & NS \\
4-Hydroxyproline & $78.80 \pm 3.50$ & $77.05 \pm 3.02$ & NS \\
Aspartic acid & $68.17 \pm 0.65$ & $68.79 \pm 0.84$ & NS \\
Threonine\| & $41.62 \pm 0.90$ & $42.05 \pm 0.46$ & NS \\
Serine\|l & $\mathbf{5 7 . 4 7} \pm 1.55$ & $56.14 \pm 0.36$ & NS \\
Proline & $61.43 \pm 0.76$ & $64.61 \pm 1.12$ & $<0.005$ \\
Glutamic acid & $100.15 \pm 2.20$ & $100.23 \pm 1.45$ & NS \\
Glycine & $202.53 \pm 3.37$ & $193.01 \pm 5.71$ & NS \\
Alanine & $52.72 \pm 0.58$ & $54.17 \pm 1.96$ & NS \\
Valine & $38.56 \pm 0.47$ & $39.38 \pm 1.06$ & NS \\
Half cystine\| & $18.97 \pm 0.55$ & $20.78 \pm 1.07$ & NS \\
Methionine & $13.79 \pm 1.05$ & $12.40 \pm 1.64$ & NS \\
Isoleucine & $30.23 \pm 0.35$ & $30.14 \pm 0.81$ & NS \\
Leucine & $68.18 \pm 0.41$ & $68.05 \pm 1.21$ & NS \\
Tyrosine & $18.24 \pm 0.50$ & $17.94 \pm 0.61$ & NS \\
Phenylalanine & $29.85 \pm 0.42$ & $30.10 \pm 0.67$ & NS \\
Hydroxylysine & $23.08 \pm 1.00$ & $23.15 \pm 0.80$ & NS \\
Lysine & $25.86 \pm 0.87$ & $25.49 \pm 1.10$ & NS \\
Histidine & $18.82 \pm 0.31$ & $17.84 \pm 0.32$ & NS \\
Arginine & $46.33 \pm 0.44$ & $44.51 \pm 0.46$ & $<0.01$ \\
\hline
\end{tabular}

Values expressed as Mean \pm SEM.

* Glomerular basement membrane.

$\ddagger$ Values in each column represent average of analyses performed on five preparations each containing the basement membrane from 17 to 25 animals.

\$ Duration of streptozotocin induced diabetes-14 mo.

|| Corrected for loss during hydrolysis as described in text.
TABLE II

Neutral Sugar and Glucosamine Content of GBM from Long Term Diabetic and Control Rats*

\begin{tabular}{lccc}
\hline & Controls & Diabetics $\ddagger$ & \\
\hline & \multicolumn{2}{c}{$(g / 100$ g basement membrane $)$} & $P$ \\
Glucose & $3.60 \pm 0.35$ & $3.71 \pm 0.42$ & NS \\
Galactose $\$$ & $4.32 \pm 0.48$ & $4.40 \pm 0.41$ & NS \\
Mannose & $0.984 \pm 0.091$ & $0.952 \pm 0.038$ & NS \\
Fucose & $0.145 \pm 0.017$ & $0.165 \pm 0.020$ & NS \\
Glucosamine & $1.69 \pm 0.07$ & $1.65 \pm 0.21$ & NS \\
\hline
\end{tabular}

Values expressed as Mean \pm SEM.

* Values in each column represent analyses performed on five preparations, each containing the basement membrane isolated from 17-25 animals.

$\ddagger$ Duration of streptozotocin induced diabetes-14 mo.

$\$$ Galactose values corrected for yield of $88 \%$.

glomerular dry weight from $5 \mathrm{mM}$ glucose during a 2-h incubation.

When glomeruli are incubated with $\left[\mathrm{U}-{ }^{14} \mathrm{C}\right]$ lysine for variable periods up to $4 \mathrm{~h}$, significant amounts of labeled lysine appear in GBM within $20 \mathrm{~min}$, and after 1 $h$ the increase of labeled lysine in GBM remains roughly linear for the duration of the incubation (Fig. 1). Significant levels of labeled hydroxylysine were not detected in GBM, however, for $60 \mathrm{~min}$ after addition of $\left[{ }^{14} \mathrm{C}\right]$ lysine to the medium. The delay in the appearance of labeled hydroxylysine in GBM could be the result of

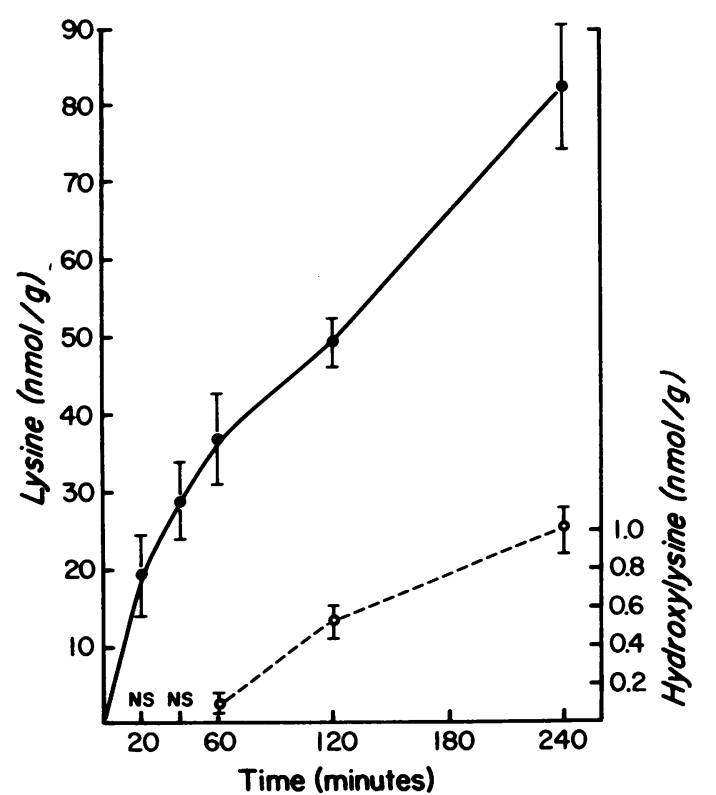

FIGURE 1 [U-14 $\mathrm{C}$ ]lysine incorporation into GBM and hydroxylation to $\left[{ }^{14} \mathrm{C}\right]$ hydroxylysine. Glomeruli incubated with 20 $\mu \mathrm{M}\left[\mathrm{U}-{ }^{14} \mathrm{C}\right]$ lysine $(312 \mathrm{mCi} / \mathrm{mmol})$. Each lysine $(\bullet-\bullet)$ and hydroxylysine (O- $-\mathrm{O})$ point represents Mean \pm SEM of five experiments. 
delayed release of newly synthesized basement membrane precursors, a possibility suggested by the studies of Grant et al. (36).

To study the time course of the appearance of $\left[{ }^{14} \mathrm{C}\right]$ hydroxylysine in GBM, pulse-chase experiments were performed. Normal glomeruli were exposed to a 1-h pulse of labeled lysine, followed by a $1-3 \mathrm{~h}$ chase with $0.25 \mathrm{mM}$ L-lysine. [U- ${ }^{14} \mathrm{C}$ ] lysine levels in GBM increased progressively up to $1 \mathrm{~h}$ after initiation of the chase period, after which labeled lysine content remained constant (Fig. 2). During the chase period the GBM content of labeled hydroxylysine increased in a roughly linear fashion. In addition to the lysine and hydroxylysine fractions, counts were determined on the effluent from the amino acid analyzer corresponding to the acidic, neutral, and other basic amino acids of GBM. No significant radioactivity was detected in these fractions. indicating that no interchange of label between lysine or hydroxylysine and other amino acids occurred during GBM synthesis.

Preliminary experiments were also performed to determine if $\left[\mathrm{U}_{-}{ }^{14} \mathrm{C}\right]$ lysine and hydroxylysine appeared in the nondialyzable fraction of the medium during pulse-chase experiments. By utilizing glomeruli from normal rats, the counts above base line appearing in lysine and hydroxylysine of the nondialyzable fraction of the medium were 9,992 and $86 \mathrm{cpm}$, respectively, after a 3 -h chase period. The total counts above base line found in lysine and hydroxylysine of the insoluble GBM during the same time period were 31,331 and $632 \mathrm{cpm}$, respectively. The values for counts in intact GBM are considerably higher than those detected in the medium. In addition, the proportion of lysine residues hydroxylated in insoluble GBM $(1.98 \%)$ was more than twice that

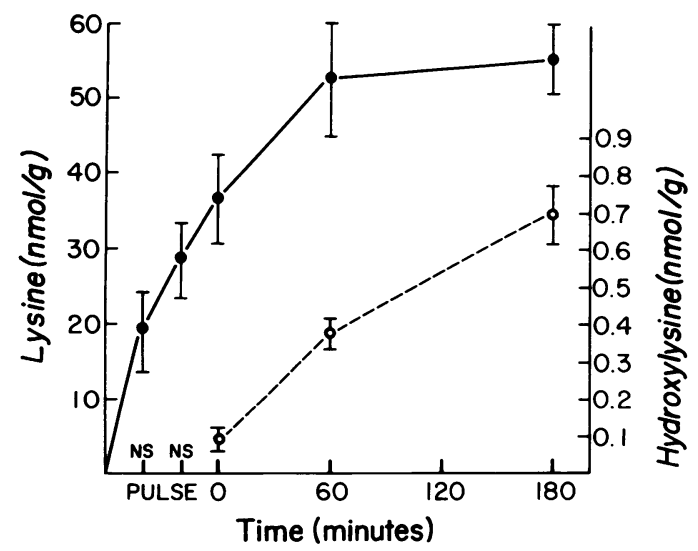

FIGURE 2 [U- $\left.{ }^{14} \mathrm{C}\right]$ lysine incorporation into GBM and hydroxylation to $\left[{ }^{14} \mathrm{C}\right]$ hydroxylysine during pulse-chase experiments. Pulse $1 \mathrm{~h} 20 \mu \mathrm{M}\left[\mathrm{U}_{-}{ }^{14} \mathrm{C}\right]$ lysine $(312 \mathrm{mCi} / \mathrm{mmol})$. Chase with $0.25 \mathrm{mM}$ L-lysine. Each lysine (--) and hydroxylysine (- - - -) point represents Mean \pm SEM of five experiments.
TABLE III

Effect of Change in Oxygen Tension on $\left[U-{ }^{14} C\right]$ Lysine Incorporation into $G B M$ and $\left[U-{ }^{14} C\right] L y$ sine Hydroxylation*

\begin{tabular}{ccc}
\hline & Lysine & Hydroxylysine \\
\hline & \multicolumn{2}{c}{ nmol $/ \mathrm{g}$ dry $G B . u_{+}^{+}$} \\
$95 \%$ Oxygen $(7) \S$ & $3.3 .52 \pm 5.29$ & $0.567 \pm 0.065$ \\
$95 \%$ Air $(7) \S$ & $24.68 \pm 3.18$ & $0.345 \pm 0.049$ \\
$P$ & $\lambda S$ & $<0.01$
\end{tabular}

* Pulse $1 \mathrm{~h}$ with $\left[\mathrm{U}-{ }^{14} \mathrm{C}\right]$ lysine $(312 \mathrm{mC} / \mathrm{mmol})$. Chase $3 \mathrm{~h}$ with L-lysine $(0.25 \mathrm{mI})$.

$\ddagger$ Mean \pm SE.M.

$\S$ Gas phase $5 \% \mathrm{CO}$.

seen in the nondialyzable portion of the medium $(0.85 \%)$.

Incubation conditions were modified to determine those optimal for the incorporation of $\left[{ }^{14} \mathrm{C}\right]$ lysine into GBM and its subsequent hydroxylation to $\left[{ }^{14} \mathrm{C}\right]$ hydroxylysine. When normal glomeruli were incubated for $4 \mathrm{~h}$ with $\left[{ }^{14} \mathrm{C}\right]$ lysine, increasing medium glucose concentration from 5 to $30 \mathrm{mM}$ did not significantly modify the incorporation of labeled lysine into GBM $(5 \mathrm{mM}$ glucose $82.52 \pm 8.26 \mathrm{nmol} / \mathrm{g}$ dry GBM, $n=5 ; 30 \mathrm{mM}$ glucose $-92.30 \pm 5.01 \mathrm{nmol} / \mathrm{g}$ dry GBM, $n=4)$. Pulsechase experiments, which more accurately reflect the incorporation of hydroxylysine containing precursors into GBM were also performed. Decreasing medium oxygen tension, as expected. led to a significant decrease in hydroxylation of labeled lysine residues, while $\left[\mathrm{U}-{ }^{14} \mathrm{C}\right.$ ] lysine incorporation, although slightly decreased, did not change significantly (Table III). When pulse-chase experiments were performed in the presence of $30 \mathrm{mM}$ glucose, no significant change in the incorporation of labeled lysine or hydroxylysine occurred $(5 \mathrm{mM}$ glucose-lysine $33.52 \pm 5.29 \mathrm{nmol} / \mathrm{g}$ dry GBM; hydroxylysine $0.567 \pm 0.065 \mathrm{nmol} / \mathrm{g}$ dry GBM, $n=7$, and $30 \mathrm{mM}$ glucose-lysine $29.92 \pm 0.77 \mathrm{nmol} / \mathrm{g}$ dry GBM; hydroxylysine $0.471 \pm 0.038 \mathrm{nmol} / \mathrm{g}$ dry GBM, $n=4)$. It was also demonstrated that the addition of $40 \mathrm{mM}$ lactate to the medium during both the pulse and chase periods did not modify the hydroxylation of labeled lysine residues in GBM.

To evaluate the effects of experimental diabetes on the incorporation of lysine and hydroxylysine containing precursors into the glomerular basement membrane, male Wistar rats were made diabetic with streptozotocin (37). Animals were considered diabetic if their plasma glucose levels consistently exceeded $300 \mathrm{mg} / 100 \mathrm{ml}$. Diabetics and age matched controls injected with buffer alone were maintained for 4-6 wk. None of the diabetic animals became ketotic, and, as expected, the weight gain of the diabetic animals $(50.7 \pm 5.74 \mathrm{~g})$ was signifi- 
cantly less than that of their controls $(127.1 \pm 10.24 \mathrm{~g})$. Glomeruli isolated from 10 to 12 diabetic or normal animals were used for each experiment. The basement membrane isolated from 10 groups of 20 diabetic animals each and control groups of similar size were analyzed for yield and lysine content. The yield of basement membrane from the glomeruli of diabetic animals expressed as dry weight of basement membrane per wet weight cortex did not differ significantly from that of controls (Table IV). The lysine content of the basement membrane from diabetic animals was also similar to that found in controls (Table IV).

Glomeruli from diabetic animals were incubated with uniformly labeled $\left[{ }^{14} \mathrm{C}\right]$ lysine for $4 \mathrm{~h}$, a time at which the apparent rate of lysine incorporation into normal basement membrane approaches linearity. As seen in Table V, the glomeruli from diabetic animals did not differ from controls in their capacity to incorporate labeled lysine into the glomerular basement membrane. To study the effect of diabetes on incorporation of hydroxylysine residues into GBM, pulse-chase experiments were performed utilizing glomeruli from diabetic animals. As can be seen in Table VI, the label found in basement membrane hydroxylysine after a 3 -h chase with cold lysine was similar when glomeruli from diabetic animals were compared with age matched controls. The $\left[\mathrm{U}_{-}{ }^{14} \mathrm{C}\right]$ lysine content of the GBM from diabetic animals also did not differ from that seen in controls (Table VI). Similar results were found when incorporation of labeled lysine and hydroxylysine were expressed as specific activities based on GBM lysine or hydroxylysine content rather than the dry weight of GBM. (Incorporation of $\left[\mathrm{U}^{14} \mathrm{C}\right]$ lysine into $\mathrm{GBM}$ after $4 \mathrm{~h}$ incubations: controls $556.3 \pm 53.3$ and diabetics $448.7 \pm$ $99.6 \mathrm{nmol} / \mathrm{mmol}$ GBM lysine, $P=\mathrm{NS}$. Pulse chase experiments, with $3 \mathrm{~h}$ chase period: [U- ${ }^{14} \mathrm{C}$ ] lysine content, control $243.2 \pm 62.6$ vs. diabetic $236.1 \pm 42.9 \mathrm{nmol} / \mathrm{mmol}$ GBM lysine and $\left[{ }^{14} \mathrm{C}\right]$ hydroxylysine content, control

\section{TABLE IV}

Yield and Lysine Content of GBM from Normal and Diabetic Rats*

\begin{tabular}{ccc}
\hline & $\begin{array}{c}\text { Percent yield } \\
\text { dry GBM /wet wt. } \\
\text { cortex }\end{array}$ & Lysine content \\
\hline & & $\mu m o l / 100 m g G B M$ \\
Normal (10) $\ddagger$ & $0.011 \pm 0.001$ & $19.1 \pm 2.2$ \\
Diabetic (10) $\ddagger$ & $0.013 \pm 0.002$ & $18.1 \pm 2.0$ \\
$P$ & NS & NS \\
\hline
\end{tabular}

Values expressed as Mean \pm SEM.

* Duration of streptozotocin induced diabetes-4-6 wk. ¥ Diabetics and normals consist of 10 groups of 20 animals each.
TABLE V

$\left[{ }^{-14} C\right]$ Lysine Incorporation into $G B M$ by Glomeruli from Diabetic Animals*

\begin{tabular}{cc}
\hline & $n$ nol $/ g$ dry GB. $U_{+}^{\ddagger}$ \\
Control (5) & $82.52 \pm 8.26$ \\
Diabetic (5) & $88.98 \pm 8.26$ \\
$P$ & NS \\
\hline
\end{tabular}

${ }^{*}$ Incubated for $4 \mathrm{~h}$ with $20 \mu \mathrm{M}\left[\mathrm{U}-{ }^{14} \mathrm{C}\right]$ lysine $(312 \mathrm{mCi} /$ mmol).

$\ddagger$ Mean \pm SEM.

$4.87 \pm 0.71$ vs. diabetic $4.90 \pm 1.07 \mathrm{nmol} / \mathrm{mmol}$ GBM hydroxylysine, $P$ for both $=$ NS).

Compositional studies performed on GBM from longterm diabetic rats (14 mo) are compared with GBM from age matched controls in Table I and II. Except for minor differences in proline and arginine content, the amino acid composition of GBM isolated from diabetic animals did not differ from controls. In addition, the carbohydrate content of the GBM from diabetic rats did not differ from that seen in controls. The similarities in GBM glucose content, a sugar found only in the disaccharide glucosyl-galactose, and in mannose and glucosamine, both of which are found only in the larger heteropolysaccharide, suggest that the content of these two subunits is unchanged in GBM from diabetic rats.

Representative samples from diabetic and control rat kidneys were examined by light microscopy by $\mathrm{Dr}$. Joseph Williamson. Examination of samples stained with haematoxylin and eosin and periodic acid Schiff reagents revealed no difference between the diabetic and control tissues. Some increase in the mesangial area and mild thickening of peripheral capillary loops was noted in diabetic tissues, but age matched control kidneys showed similar changes. Similar histologic changes have previously been noted in association with aging alone in man and other species $(38,39)$.

\section{TABLE VI}

$\left[U-{ }^{14} C\right]$ Lysine Incorporation into $G B M$ and $\left[U-{ }^{14} C\right]$ Lysine Hydroxylation by Glomeruli from Diabetic Animals*

\begin{tabular}{|c|c|c|c|}
\hline & Lysine & Hydroxylysine & $\begin{array}{l}\text { Percent total } \\
\text { cpm in } \\
\text { hydroxylysine }\end{array}$ \\
\hline \multicolumn{4}{|c|}{$n \mathrm{~mol} / \mathrm{g} d r y G B .1 I$} \\
\hline Control (7) & $33.52 \pm 5.29$ & $0.567 \pm 0.065$ & $1.85 \pm 0.290$ \\
\hline Diabetic (7) & $28.72 \pm 2.99$ & $0.473 \pm 0.082$ & $1.61 \pm 0.186$ \\
\hline$P$ & NS & NS & NS \\
\hline
\end{tabular}

Values expressed as Mean $\pm \mathrm{SEM}$.

* Pulse $1 \mathrm{~h}$ with $20 \mu \mathrm{M}\left[\mathrm{U}^{-14} \mathrm{C}\right]$ lysine $(312 \mathrm{mCi} / \mathrm{mmol})$, chase $3 \mathrm{~h}$ with $0.25 \mathrm{mM}$ L-lysine. 


\section{DISCUSSION}

The isolated glomerular preparation provides useful information regarding basement membrane synthesis and factors responsible for its regulation. Labeled lysine is rapidly incorporated into the basement membrane, and after $1 \mathrm{~h}$ the apparent rate of incorporation of $\left[\mathrm{U}-{ }^{14} \mathrm{C}\right]$ lysine into GBM proceeds in a linear fashion. Pulsechase experiments demonstrate that a 60-min interval occurs before significant counts appear in GBM hydroxylysine, suggesting a delay in the release of hydroxylysine containing GBM precursors similar to that noted in the biosynthesis of interstitial collagens and other basement laminae $(36,40,41)$. Once hydroxylated lysyl residues are detected in GBM, there is a progressive linear increase in labeled hydroxylysine for the duration of the incubation. In pulse-chase experiments this occurs without a further increase in labeled lysine, raising the possibility that incorporation of lysyl residues into a GBM precursor precedes hydroxylation. Conversely, the small percentage of labeled lysyl residues hydroxylated after a $4 \mathrm{~h}$ incubation (Fig. 1) relative to the proportion of lysine residues subsequently hydroxylated in rat GBM (Table I) could indicate that the hydroxylysine rich precursor accounts for a relatively small proportion of the newly synthesized GBM, as suggested by Grant et al. (36). This could also reflect the slow turnover of GBM previously noted by several investigators $(42,43)$.

Pulse-chase experiments performed with glomeruli from diabetic animals demonstrated no significant change in the incorporation of labeled hydroxylysine into the GBM when compared with controls. This probably represents equal rates of deposition of hydroxylysine containing GBM precursor into insoluble GBM by diabetic and control tissues $(36,40)$, although little information is available regarding the characterization of precursors accounting for the bulk of GBM synthesis. The production of equal amounts of hydroxylysine containing precursors by diabetic and normal glomeruli also suggests normal activity of lysyl hydroxylase in the diabetics, although increased intracellular levels of newly hydroxylated GBM precursors cannot be excluded.

Several recent studies, utilizing embryonic chick lens (36) and the embryonic rat parietal yolk sac (40) have demonstrated the production of a soluble collagen-like basement membrane precursor when these tissues are incubated with labeled proline or lysine. In these metabolically active tissues as in isolated glomeruli, the basement membrane precursor accounts for only a small proportion of newly labeled soluble protein. The preliminary studies reported here indicate that counts in both lysine and hydroxylysine in insoluble GBM exceed those in the medium during incubations performed with isolated glomeruli. suggesting that under these experi- mental conditions the quantification of label in a soluble GBM precursor rather than insoluble GBM would not be a more sensitive indicator of GBM synthesis. Information gained with embryonic tissues is of great interest, although it has yet to be established that these tissues are subject to the same metabolic controls found in glomeruli from more mature animals. In addition, it would be different to utilize embryonic tissues for longterm studies of the pathogenesis of basement membrane thickening which characteristically occur over months to years. The recent studies of Grant et al. (44) with isolated rat glomeruli do indicate that collagen like precursors, similar to those found in embryonic tissues exist for GBM, and suggest that useful information may be gained from performing comparative studies with normal and diabetic animals.

The failure to demonstrate increased incorporation of a hydroxylysine rich precursor into GBM by glomeruli from diabetic animals is not surprising since the GBM isolated from long term diabetic rats did not demonstrate an increased hydroxylysine content relative to controls. In addition to normal hydroxylysine values, the GBM from diabetic rats fails to demonstrate an increase in its covalently bound disaccharide glycosyl-galactose, as well as the increased levels of hydroxyproline and glycine and decreases in lysine, valine, and tyrosine previously found in the GBM from patients with long term diabetes $(14,15)$. The change previously noted in the chemical composition of human GBM may be quite specific for the diabetic state (30), although two recent studies have failed to consistently find a significant change in the chemical composition of the GBM in diabetic patients $(45,46)$.

Although incorporation of labeled hydroxylysine into GBM is a more specific indicator of basement membrane synthesis, the normal rates of incorporation of labeled lysine into GBM by glomeruli from diabetic animals also fails to suggest the overproduction of GBM secondary to streptozotocin induced diabetes. The minimal thickening of the GBM noted in an earlier study of glomeruli from long term streptozotocin diabetic rats (13), and the similarity of the morphology of diabetic and control glomeruli in the present study support this conclusion. In addition, the extensive glomerulosclerosis sometimes seen in diabetic patients has not been described in the kidneys of rats with long term experimental diabetes. Although it is possible that the 3-yr life span of the rat is too short for one to see significant GBM thickening or changes in GBM chemical composition, the replacement time of approximately $1 \mathrm{yr}$ for rat GBM noted by Walker (43) should allow one to detect characteristic quantitative and qualitative changes if they were to occur in long term diabetic animals.

Several other studies have been interpreted as demon- 
strating increased GBM synthesis in association with experimental diabetes in the rat. Spiro and Spiro demonstrated increased activity of renal cortical glucosyl transferase in alloxan diabetic rats and partial reversal toward normal after institution of insulin therapy (17). Unfortunately, renal galactosyl transferase, the enzyme which adds the initial sugar residue to hydroxylysine, did not demonstrate sufficient activity to allow comparison in diabetic and normal animals. In addition, the prompt glycosylation of newly hydroxylated lysyl residues demonstrated in more recent biosynthetic studies of the basement membrane of chick lens suggests that lysine hydroxylation is the step where regulation may limit GBM synthesis and extrusion from cell (36). Cohen and Vogt (18) have demonstrated increased incorporation of labeled lysine into glomerular proteins by glomeruli isolated from streptozotocin diabetic rats and more recently Khalifa and Cohen (19) have presented evidence suggesting increased lysyl hydroxylase activity in the soluble fraction of homogenates from diabetic animals. Wahl and his colleagues, however, were unable to demonstrate increased incorporation of labeled glucose into the GBM in studies utilizing glomeruli from diabetic rats (20).

Considerable confusion exists regarding the relationship of the metabolic changes associated with diabetes to the progression of diabetic microvascular disease. The present study suggests that chronic streptozotocin induced diabetes is not associated with changes in the biosynthesis, chemical composition, or morphology of the GBM. Biosynthetic $(18,19)$ and compositional (14, $15,47)$ studies in both experimental animals and diabetic patients, however, have suggested that hyperglycemia, insulin deficiency, or other metabolic abnormalities associated with diabetes may play an important role in the progression of diabetic capillary disease. The application of newer biochemical (44) and more rigorous morphometric techniques $(48,49)$ may eventually provide information on the role played by environmental and hereditary factors in the pathogenesis of diabetic microvascular disease.

\section{ACKNOWLEDGMENTS}

The author wishes to thank Miss Sigrun Konopka for expert technical assistance, and Dr. Albert I. Winegrad for reviewing the manuscript.

This work was supported in part by a grant-in-aid from the American Heart Association, no. 71-763.

\section{REFERENCES}

1. Bloodworth, J. M. B., Jr. 1963. Diabetic microangiopathy. Diabetes. 12 : 99-114.

2. Goldenberg, S., M. Alex, R. A. Joshi, and H. T. Blumenthal. 1959. Nonatheromatous peripheral vascular disease of the lower extremity in diabetes mellitus. $D i$ abctes. $8: 261-273$.

3. Deckert, T., and J. E. Poulsen. 1968. Prognosis for juvenile diabetics with late diabetic manifestations. Acta Med. Scand. 183 : 351-356.

4. Entmacher, P. S., H. F. Root, and H. H. Marks. 1964. Longevity of diabetic patients in recent years. Diabetes. 13: 373-377.

5. Kimmelstiel, P., and C. Wilson. 1936. Intercapillary lesions in the glomeruli of the kidney. Am. J. Pathol. 12: 83-96. (And Plates 9-12.)

6. Bergstrand, A., and H. Bucht. 1957. Electron microscopic investigations on the glomerular lesions in diabetes mellitus (diabetic glomerulosclerosis). Lab. Invest. 6 : 293-300.

7. Farquhar, M. G., J. Hopper, Jr., and H. D. Moon. 1959. Diabetic glomerulosclerosis: electron and light microscopic studies. Am. J. Pathol. 35: 721-753.

8. Treser, G., W. Oppermann, T. Ehrenreich, K. Lange, R. Levine, and R. A. Camerini-Davalos. 1968. Glomerular lesions in a strain of genetically diabetic mice. Proc. Soc. Exp. Biol. Med. $129: 820-823$.

9. Like, A. A., R. L. Lavine, P. L. Poffenbarger, and W. L. Chick. 1972. Studies in the diabetic mutant mouse. VI. Evolution of glomerular lesions and associated proteinuria. Am. J. Pathol. 66: 193-224.

10. Bloodworth, J. M. B., Jr., R. L. Engerman, and K. L. Powers. 1969. Experimental diabetic microangiopathy. 1. Basement membrane statistics in the dog. Diabetes. 18: $455-458$.

11. Ørskov, H., T. S. Olsen, K. Nielsen, O. J. Rafaelsen, and K. Lundbaek. 1965. Kidney lesions in rats with severe long-term alloxan diabetes. I. Influences of age, alloxan damage, and insulin administration. Diabetologia. $1: 172-179$.

12. Hagg, E. 1974. Glomerular basement membrane thickening in rats with long-term alloxan diabetes. Acta Pathol. Microbiol. Scand. Section A. 82: 211-219.

13. Cameron, D. P., M. Amherdt, P. Leunberger, L. Orci, and W. Stauffacher. 1973. Microvascular alterations in chronically streptozotocin-diabetic rats. In Early Diabetes. R. A. Camerini-Davalos and H. S. Cole, editors. Academic Press, Inc., N. Y and London. 257-269.

14. Beisswenger, P. J., and R. G. Spiro. 1970. Human glomerular basement membrane: chemical alteration in diabetes mellitus. Science (Wash. D. C.). 168: 596-598.

15. Beisswenger, P. J., and R. G. Spiro. 1973. Studies on the human glomerular basement membrane. Composition, nature of the carbohydrate units and chemical changes in diabetes mellitus. Diabetes. 22: 180-193.

16. Hudson, B. G., and R. G. Spiro. 1972. Fractionation of glycoprotein components of the reduced alkylated renal glomerular basement membrane. J. Biol. Chem. 247: 4239-4247.

17. Spiro, R. G., and M. J. Spiro. 1971. Effect of diabetes on the biosynthesis of the renal glomerular basement membrane. Studies on the glucosyltransferase. Diabetes. 20: $641-648$.

18. Cohen, M. P., and C. Vogt. 1972. Evidence for enhanced basement membrane synthesis and lysine hydroxylation in renal glomerulus in experimental diabetes. Biochem. Biophys. Res. Commun. 49: 1542-1546.

19. Khalifa, A., and M. P. Cohen. 1975. Glomerular protocollagen lysyl-hydroxylase activity in streptozotocin diabetes. Biochim. Biophys. Acta. 386: 332-339.

20. Wahl, P., D. Deppermann, W. Deschner, E. Fuchs, and W. Rexroth. 1973. The metabolism of the isolated renal glomerulus and its basement membranes. In Early Diabetes, R. A. Camerini-Davalos and H. S. Cole, editors. Academic Press, Inc., N. Y. and London. 147-153. 
21. Fong, S. C. J., and K. N. Drummond. 1968. Method for preparation of glomeruli for metabolic studies. J. Lab. Clin. Med. 71: 1034-1039.

22. Walker, W. G., and H. N. Hulter. 1969. Some observations on the metabolic activity of glomeruli. Trans. Am. Clin. Climatol. Assoc. 81: 174-183.

23. Bruchhausen, F. V. 1971. Zur Biosynthese der Basalmembran. Über die verwertung von Prolin und Glucose zum Aufbau von Bestandteilen der glomerulären Basal membran in vitro. Naun'n-Schmiederberg's Arch. Pharmacol. 268 : 83-95.

24. Meezan, E., K. Brendel, J. Ulreich, and E. C. Carlson. 1973. Properties of a pure metabolically active glomerular preparation from rat kidneys. I. Isolation. J. Pharmacol. Exp. Ther. 187: 332-341.

25. Spiro, R. G. 1970. Glycoproteins. Annu. Rẽ. Biochem. 39: 599-638.

26. Spiro, R. G. 1967. Studies on the renal glomerular basement membrane, nature of the carbohydrate units and their attachment to the peptide portion. J. Biol. Chcm. 242: 1923-1932.

27. Hohorst, Hans-Jürgen. 1963. L- $(+)$-lactate. Determination with lactic dehydrogenase and DPN. In Methods of Enzymatic Analysis. H.-U. Bergmeyer, editor. Academic Press, Inc., N. Y. and London. 266-270.

28. Rodbell, M. 1964. Metabolism of isolated fat cells. I. Effects of hormones on glucose metabolism and lipolysis. J. Biol. Chem. 239 : 375-380.

29. Steinberg, D., and S. Udenfriend. 1957. The measurement of radioisotopes. In Methods in Enzymology, S. P. Colowick and N. O. Kaplan, editors. Academic Press, Inc., N. Y. 425-472.

30. Beisswenger, P. J. 1973. Specificity of the chemical alteration in the diabetic glomerular basement membrane. Diabctes. 22: 744-750.

31. Mahieu, P., and R. J. Winand. 1970. Chemical structure of tubular and glomerular basement membranes of human kidney. Isolation, purification, carbohydrate and amino acid composition. Eur. J. Biochem. 12: 410-418.

32. Westberg. N. G., and A. F. Michael. 1970. Human glomerular basement membrane, preparation and composition. Biochemistry. 9: 3837-3846.

33. Spiro, R. G. 1967. Studies on the renal glomerular basement membrane. Preparation and chemical composition. J. Biol. Chcm. 242: 1915-1922.

34. Blau, E., and A. F. Michael. 1971. Rat glomerular basement membrane composition and metabolism in aminonucleoside nephrosis. J. Lab. Clin. Mcd. 77: 97-109.

35. Kefalides, N. A. 1970. Comparative biochemistry of mammalian basement membranes. In Chemistry and Molecular Biology of the Intercellular Matrix. E. A. Balazs, editor. Academic Press, Inc., London and N. Y., 535-573.
36. Grant, M. E., N. A. Kefalides, and D. J. Prockop. 1972. The biosynthesis of basement membrane collagen in embryonic chick lens. I. Delay between the synthesis of polypeptide chains and the secretion of collagen by matrix-free cells. J. Biol. Chem. 247: 3539-3544.

37. Junod, A., A. E. Lambert, W. Stauffacher, and A. E. Renold. 1969. Diabetogenic action of streptozotocin: relationship of dose to metabolic response. J. Clin. In''est. 48 : 2129-2139.

38. Kurtz, S. M., and J. F. A. McManus. 1959. A reconsideration of the development, structure, and disease of the human glomerulus. Am. Heart J. 58: 357-371.

39. Bloodworth, J. M. B., R. L. Engerman, R. A. Camerini-Davalos, and K. L. Powers. 1970. Variations in capillary basement membrane width produced by aging and diabetes mellitus. In Early Diabetes, R. A. Camerini-Davalos and H. S. Cole, editors. Advances in Metabolic Disorders. Academic Press, Inc., N. Y. (Suppl. 1) 279-295.

40. Clark, C. C., E. A. Tomichek, T. R. Koszalka, R. L. Brent, and N. A. Kefalides. 1973. Basement membrane biosynthesis in rat parietal yolk sac. Fed. Proc. 32: 650ABS. (Abstr.)

41. Dehm, P., and D. J. Prockop. 1971. Synthesis and extrusion of collagen by freshly isolated cells from chick embryo tendon. Biochim. Biophy's. Acta. 240: 358-369.

42. Lazarow, A., and E. Speidel. 1964. The chemical composition of the glomerular basement membrane and its relationship to the production of diabetic complications. In Small Blood Vessel Involvement in Diabetes Mellitus. Amer. Inst. Biol. Sci. Publ. 127-159.

43. Walker, F. 1973. The origin, turnover and removal of glomerular basement-membrane. J. Pathol. 110: 233-244.

44. Grant, M. E., R. Harwood, and I. F. Williams. 1975. The biosynthesis of basement-membrane collagen by isolated rat glomeruli. Eur. J. Biochem. 54: 531-540.

45. Westberg, N. G., and A. F. Michael. 1973. Human glomerular basement membrane: chemical composition in diabetes mellitus. Acta Med. Scand. 194: 39-47.

46. Kefalides, N. A. 1974. Biochemical properties of human glomerular basement membrane in normal and diabetic kidney. J. Clin. Iniest. 53 : 403-407.

47. Beisswenger, P. J. 1975. Chemical composition of glomerular basement membrane (GBM) in short-term diabetes. Diabctes. 24: Suppl. 2, 427. (Abstr.)

48. Osterby, R. 1972. Morphometric studies of the peripheral glomerular basement membrane in early juvenile diabetes. I. Development of initial basement membrane thickening. Diabctologia. 8: 84-92.

49. Østerby, R. 1973. Morphometric studies of the peripheral glomerular basement membrane. II. Topography of the initial lesions. Diabctologia. 9: 108-114. 